\section{Gene Doping: The Undetectable Performance-Enhancing Drug?}

\section{Paige Dyrek and Christopher S. Lee*}

Stetson Powell Orthopaedics and Sports Medicine, USA

\begin{abstract}
Several high profile athletes have incorporated performance-enhancing drugs (PEDs) into their training regimen, and there is speculation that a fair number of professional, collegiate, and recreational athletes are engaging in these practices as well. With better technology, however, current doping methods are becoming easier to detect. Because of this, some athletes will soon be looking for other ways to become the best. This commentary reviews gene therapy in the form of doping with a focus on Erythropoietin (Epo), VEGF, and IGF-1. We also review the possible long-term effects including cancer, heart failure, and stroke and discuss the detectability of gene doping in the future.
\end{abstract}

Keywords: Performance-enhancing drugs; Gene therapy; Gene doping; Erythropoietin; Insulin like growth factor; Vascular Endothelial growth factor

\section{Introduction}

In the eyes of an elite athlete, there is no accomplishment greater than being the strongest, the fastest, and simply the best. Historically, becoming the best required more than just fine-tuning raw and extraordinary talent. It entailed painstaking preparation, selfsacrifice, and unwavering determination. Today, however, the level of competition that exists in the field of professional athletics is so high that premier athletes can no longer rely on inherited genes and oldfashioned hard work. Instead, some athletes succumb to dangerous opportunities, like performance-enhancing drugs (PEDs), that promise faster times, stronger muscles, quicker recoveries, and increased concentration. Although many performance-enhancing drugs live up to their name and have been used for several years, they are becoming increasingly easier to detect with biotechnological advancements. Thus, some fraudulent athletes may eventually trial a different type of PED called gene therapy [1-6], the gold standard of doping. First addressed in 2001 by the International Olympic Committee and later prohibited in 2003 by the World Anti-Doping Agency (WADA), gene doping has raised concerns for several years [7-15]; however there is no definitive evidence to support that gene therapy has ever been used as a form of athletic enhancement. This short commentary analyzes gene doping in its infancy as the ultimate performance-enhancing method and threat to sports as we know it.

\section{Gene Therapy}

In the simplest of definitions, "gene therapy is adding or altering genes in cells within the body in order to treat a disease" [13]. With use of a vector, the corrected copy of a gene can be injected into somatic cells where they are subsequently translated into a functioning protein. Alternatively, an ex vivo approach can also be implemented where cells are taken from the patient, genetically modified in cell culture, and then returned [15]. Since 1990, gene therapy has shown success in human clinical trials involving immune deficiencies, hemophilia, and hereditary blindness and it continues to show promise in tackling the likes of HIV, Parkinson's, and ALS $[1,5,16]$. However, like many therapeutic mechanisms, gene therapy comes with a risk of abuse, specifically in elite athletes.

\section{Possibilities}

Although there is no evidence to support that gene therapy is currently being used as a doping method in athletes, it carries an unbelievable promise toward increasing oxygen delivery, glucose metabolism, and muscle growth [7]. In endurance sports where athletes must have a high oxygen carrying capacity, the applicability of gene therapy to Erythropoietin (Epo) doping is nothing short of appealing. Epo is a glycoprotein hormone released by the kidney in an effort to increase red blood cell production and subsequent oxygen carrying capacity in hypoxic environments [15]. Although blood doping with Epo has been illegally used for several years in endurance athletes, gene doping has become a topic of interest because of its long-lasting effects. Studies in mice have shown that Epo vectors can significantly increase the hematocrit level for a minimum of four months [12]. In addition, Rivera et al. documented regulated Epo expression from a single injection in rhesus macaques after 6 years. Aside from Epo, insulin-like growth factor 1 (IGF-1) and vascular endothelial growth factor (VEGF) are also other likely targets of gene dopers $[7,10,14]$. IGF-1 vectors would aid in muscle development, repair while VEGF would increase angiogenesis, and therefore blood flow.

\section{Doping Risks}

Although many elite athletes and their coaches entertain the idea of gene doping, the potential risks cannot be overlooked. It is well known that overexpressed Epo can cause stroke and heart failure due to the viscosity of the circulating blood [14]. That risk may be even greater and more pronounced in gene doping because production levels cannot be easily controlled [13]. In 2004, Guangping Gau et al. studied the delivery of Epo through use of a viral vector in cynomolgus macaques and reported, "many animals required repeated therapeutic phlebotomies to maintain nontoxic hematocrits" after just one injection [6]. In addition, uncontrollable muscle growth through IGF1 vectors would likely cause tendon tears or fractures [14]. Perhaps more astounding is the potential to develop cancer from gene therapy treatments. In 2002, a three-year-old boy being treated by gene therapy for severe combined immune deficiency (SCID) developed leukemia [2]. Because we have no control over where retroviral vectors insert themselves, it is extremely possible that the vector inserted itself into a gene that controlled cell growth and proliferation, thus causing cancer [2]. In 2003 and 2005, gene therapy suffered more major setbacks as two other children developed cancer $[3,4]$.

*Corresponding author: Christopher S Lee, $191 \mathrm{~S}$. Buena Vista Street \#470 Burbank, CA 91505, USA, Tel: (818) 848-3030; Fax: (818) 848-2228; E-mail: pdyrek@westernu.edu, chrisleemd08@gmail.com

Received May 21, 2015; Accepted June 18, 2015; Published June 26, 2015

Citation: Paige MD, Christopher SL (2015) DGene Doping: The Undetectable Performance-Enhancing Drug?. J Sports Med Doping Stud 5: 162. doi:10.4172/2161-0673.1000162

Copyright: $\odot 2015$ Paige MD, et al. This is an open-access article distributed under the terms of the Creative Commons Attribution License, which permits unrestricted use, distribution, and reproduction in any medium, provided the original author and source are credited. 


\section{Detection}

One of the reasons gene doping has received so much attention is because it is believed to be impossible to detect. If a gene is modified and then transfected into the body's cells, the proteins that are produced should be completely identical to the physiological ones, right? François Lasne and colleagues say no. In 2004, they compared the isoelectric profiles of physiological Epo and Epo resulting from in vivo gene transfer in primates. They found that induction of exogenous Epo resulted in over expression and thus a different isoelectric pattern than the endogenous form [8]. However, other articles suggest that detection will be next to impossible $[7,10,14,15]$. In cases where proteins are not secreted from cells, the only way for detection would be through multiple biopsies, which athletes would not tolerate $[7,10]$. Even with advanced biotechnology, gene doping may not always be detected. If gene doping ever does become a reality in sports, it should be no surprise if some stellar, super human athletes slip through the cracks.

\section{Conclusion}

Performance-enhancing drugs have changed the world of sports. Some athletes who were once revered as heroes are now merely associated with fraud. Although morals may change, the determination to win is all still the same. With gene therapy at the forefront of medicine, there is potential for athletes to find a new way to the finish line. In endurance athletes, Epo vectors can increase oxygen carrying capacity longer than current performance-enhancing methods and VEGF vectors can increase angiogenesis and aerobic performance. The advantage to all of this over traditional PEDs is that some gene doping is expected to be extremely difficult to detect. Especially in the early stages, it is possible that athletes will outsmart current technology. Being a winner through genetic enhancement, however, isn't all that it seems. Gene doping can lead to serious long-term effects including stroke, cardiovascular disease, or cancer. However, with an unwavering will to win, some athletes might dismiss these effects if genetic enhancement means being the best. For now, gene doping is still in the form of gene therapy, which has the potential to save millions of desperate lives. We should not be surprised, however, if our beloved athletes soon become stronger, faster, and somewhat super human.

\section{Reference}

1. Azzouz M (2004) VEGF delivery with retrogradely transported lentivector prolongs survival in a mouse ALS model. Nature 429: 413-417.

2. Check E (2002) A tragic setback. Nature 420: 116-118.

3. Check E (2003) Second cancer case halts gene-therapy trials. Nature 421: 305.

4. Check E (2005) Gene therapy put on hold as third child develops cancer Nature 433: 561 .

5. Edelstein ML, Abedi MR, and Wixon J (2007) Gene therapy clinical trials worldwide to 2007-- an update. J Gene Med 9: 833-842.

6. Gao G (2004) Erythropoietin gene therapy leads to autoimmune anemia in macaques. Blood 103: 3300-3302.

7. Gould D (2013) Gene doping: gene delivery for olympic victory. Br J Clin Pharmacol 76: 292-298.

8. Lasne F (2004) "Genetic Doping" with erythropoietin cDNA in primate muscle is detectable. Mol Ther 10: 409-410.

9. Lippi G, Guidi GC (2004) Gene manipulation and improvement of athletic performances: new strategies in blood doping. Br J Sports Med 38: 641.

10. McCrory P (2003) Super athletes or gene cheats? Br J Sports Med 37: 192193.

11. Pokrywka A (2013) Genes in sport and doping. Biol Sport 30: 155-161.

12. Rivera VM (2005) Long-term pharmacologically regulated expression of erythropoietin in primates following AAV-mediated gene transfer. Blood 105 1424-1430.

13. Schjerling P (2005) Genetic Technology and Sport (1stedn) The Basics of Gene Doping, ed. M. McNamee and J. Parry. New York: Routledge.

14. Unal M, DO Unal (2004) Gene doping in sports. Sports Med 34: 357-362.

15. Wells DJ (2008) Gene doping: the hype and the reality. Br J Pharmacol 154 623-631.

16. Yu M, Poeschla E, Wong-Staal F(1994) Progress towards gene therapy for HIV infection. Gene Ther 1: 13-26. 